\title{
RURAL BIOENERGY SUSTAINABLE DEVELOPMENT THROUGH TRANSITION TO TRIGENERATIONS
}

\author{
Dmitrijs Rusovs, Sigurds Jaundalders, Peteris Stanka \\ Riga Technical University, Latvia \\ dmitrijs.rusovs@rtu.lv, sigurds.jaundalders@rtu.lv, peteris.stanka@1v.bosch.com
}

\begin{abstract}
Distributed generation by combined heat and power plants (CHP) converting biomass into heat and electrical energy becomes more common in Latvia. More than 60 bio mass plants are in operation. In many cases reductions of revenues from feed-in tariffs for biomass electricity exported into the grid challenge the existence of decentralized power system. The focus of this paper is assessment of trigeneration for rural biomass CHP. Trigeneration assumes bioenergy conversion in power, heat energy for space heating and cooling by sorption chiller simultaneously. Chilled water is usually used for air conditioning. However, in mild climate conditions chilled water demand is limited. Therefore, combination of sorption cooling and vapor-compression refrigeration driven by dual source (heat and/or electrical energy) were evaluated with the purpose to get break-even cooling temperature for trigeneration introduction. The refrigerant ammonia (R717) is used for associated conventional vapor-compression cycles calculation. Mainly hybrid refrigeration performances are considered for food freezing applications (at evaporation temperature in range from $-10^{\circ} \mathrm{C}$ to $-20^{\circ} \mathrm{C}$ and condensing temperature from $+10^{\circ} \mathrm{C}$ to $+30^{\circ} \mathrm{C}$ ). Since sorption processes consume heat energy at different temperature level rejected heat from various generation technologies like water steam turbine, organic Rankin cycle and internal combustion engine were considered. Energy analyses of bio energy based combined cooling, heat and power plant (CCHP) were carried out in order to get the primary energy saving system indexes for low temperature refrigeration.
\end{abstract}

Keywords: bioenergy, trigeneration, refrigeration, sorption, chiller.

\section{Introduction}

The International Renewable Energy Agency (IRENA) represent in the report "Renewable power generationcosts in 2017" [1] the average lifetime leveled cost of electrical generation LCOE for renewable energy sources represented as

$$
L C O E=\frac{\sum_{t=1}^{n} \frac{I_{t}+M_{t}+F_{t}}{(1+r)^{t}}}{\sum_{t=1}^{n} \frac{E_{t}}{(1+r)^{t}}},
$$

where $I_{t}$ - investment expenditures in the year $\mathrm{t}$;

$M_{t}$ - operations and maintenance expenditures in the year $\mathrm{t}$;

$F_{t}$ - fuel expenditures in the year t;

$E_{t}$ - electricity generation in the year $\mathrm{t}$;

$r$ - discount rate;

$n-$ life of the system, year.

The report suggests that global average cost of electrical energy is about $0.05 \mathrm{USD} \cdot \mathrm{kWh}$ for onshore wind and $0.06 \mathrm{USD} \cdot(\mathrm{kWh})^{-1}$ for solar PV. Biomass utility-scale renewable power generation technologies resulted in the price for electrical energy of $0.07 \mathrm{USD} \cdot(\mathrm{kWh})^{-1}$.

Competitive procurement of electrical power in North Europe represents auction prices in average range from 40.00 to $50.00 \mathrm{EUR} \cdot \mathrm{MWh}$ (https://www.nordpoolgroup.com/Market-data1/\#/nordic/chart).

Distributed generation by combined heat and power plants (CHP) converting biomass into heat and electrical energy became common in Latvia. Supplier is entitled to sell the produced electricity within the framework of the mandatory procurement, if he performs according to the efficiency criteria by the "Regulations Regarding Electricity Production and Price Determination upon Production of Electricity in Cogeneration" adopted in 10 March 2009 by the Republic of Latvia Cabinet Regulation No. 221 [2]. The regulation suggests feed-in tariffs for biomass electricity exported into the grid. According to the the International Energy Agency (https://www.iea.org) in $2015799 \mathrm{GWh}$ or $14 \%$ of $5533 \mathrm{GW}$ htotal electricity generation of Latvia was produced from biofuels. Reduction of revenues from feed-in tariffs for biomass electricity exported into the grid can challenge existence of the decentralized power system in many cases. Latvian climate conditions are 
favorable for heat energy consumption because the space-heating season is accountable for around seven months per year. However, recent climate warming, building energy saving implementation and non-heating periods request to develop additional heat consumption. Trigeneration for rural biomass CHP assumes bioenergy conversion in power, heat energy for space heating and cooling by sorption chiller simultaneously [3]. Chilled water is usually used for air conditioning; however, the demand for it is limited by Latvian mild summers. Therefore, suggested hybrid combination of sorption cooling and the traditional vapour compression device targeted to produce cooling at low temperature in the range from $-10{ }^{\circ} \mathrm{C}$ to $-20^{\circ} \mathrm{C}$.

\section{Materials and methods}

Energy sources for the considered biopower energy plant can be divided into two groups of fuel types: solid biomass and biogas from fermentation tanks. Depending on the fuel kind various thermal engine solution can be considered. As an example, for solid biomass it will be useful to apply water or organic Rankine Cycle [4]. In case of biomass gasification the internal combustion engine or microturbine will be an efficient solution. However, solid biomass gasification evolves additional heat fluxes consideration and therefore was not in the scope of the presented work. Biogas production in fermentation tanks now is realized in more than 60 operational bio gas plants in Latvia. High efficient internal combustion engine is a common solution for biogas conversion in electrical and heat energy. Other types of solution, like the Stirling engine or fuel cell are not yet widely used in Latvia for bioenergy generation.

It is very important to select an efficient way of waste heat recovering in refrigeration systems with the target to get cooling in the range from $-10{ }^{\circ} \mathrm{C}$ to $-20{ }^{\circ} \mathrm{C}$. For these purposes we consider hybrid cooling.

Water -LiBr absorption chillers with single and double-effect were considered for different climate zones in Algeria [5]. The results show that the Broad double-effect water-LiBr absorption chiller can reach COP up to 1.2 and 1.3 , but Yazaki single-effect water-LiBr absorption chiller remains at COP from 0.6 to 0.7 . We can consider that cooling cycle combination can result in better efficiency. But water-LiBr absorption is limited by water freezing temperature. Due to that other agents should be selected.

The performance of combination of the vapor compressor and adsorbent bed thermal compressor using ammonia was simulated in [6] and demonstrates total efficiency for evaporating temperature $\left(-5^{\circ} \mathrm{C}\right.$ to $\left.+20^{\circ} \mathrm{C}\right)$ in the range of COP between 0.24 to 0.76 . However, this temperature range is not sufficient for our target. Therefore, the absorption cycle can be used with the purpose to reach the target temperature range.

Comparison of primary energy efficiency of absorption-compression hybrid refrigeration is better by $29 \%$ than for double-effect absorption refrigeration [7]. Also, application of the compressor provides a wider working condition - evaporation temperatures reach $-26{ }^{\circ} \mathrm{C}$, but double-effect absorption can perform at the lowest evaporation $-2{ }^{\circ} \mathrm{C}$.

Brief review of hybrid cooling proves our selection in favor of ammonium and absorptioncompression hybrid refrigeration. Most of refrigeration studies do not take in account the waste heat of the thermal engine, but trigeneration study is focused on single-effect absorber chiller. Our paper suggests hybrid cooling in combination with thermal engine balance, described below.

Trigeneration unit in Fig. 1 consists of a thermal engine with an electrical generator, heat energy recovery device for exhaust gas heat utilization, absorption chiller and a vapor compression refrigeration unit. The hybrid cooling system includes the absorber evaporator with direct energy consumption from refrigeration condenser. The combination of the absorber evaporator and vapor compression condenser in a single unit will allow decreasing of the condensing temperature and therefore refrigerant compression work becomes smaller. With the purpose to consider energy balance of the suggested trigeneration system the following equations are presented below.

Biofuel combustion heat $Q_{c o m}$ will be converted in the thermal engine to $W_{e}$ electrical energy and $Q_{e h}$ exhausted heat (including cooling of oil and the engine jacket, if needed):

$$
Q_{\text {com }}=W_{e}+Q_{e h} ;
$$




$$
\eta_{e}=\frac{W_{e}}{Q_{c o m}},
$$

where $\eta_{e}$ - eficiency of energy conversation depends on the type of the thermal engine, for example, internal combustion engine $\eta_{e}=0.35$, for back pressure water steam turbine or organic Rankine cycle it can be lower as 0.25 .

Energy balance of exhausted heat can be described, as

$$
Q_{e h}=Q_{h c}+Q_{a g}+Q_{f g},
$$

where $Q_{h c}$-thermal power (heat power of cogeneration);

$Q_{a g}$ - heat power for the absorber generator (heat consumption of absorption chiller).

Assume, that all $Q_{e h}$ exhaust heat of the thermal engine is used only for absorption chiller, so $Q_{h c}=0$. But flue gas energy is consisting of just $10 \%$ of $Q_{e h}$, then

$$
Q_{a g}=0.9 Q_{\text {com }}\left(1-\eta_{e}\right) .
$$

Refrigeration part of the trigeneration unit consists of two systems: absorption chiller with efficiency $C O P_{a c}$ and vapor compression set with performance $C O P_{r}$

$$
C O P_{a c}=\frac{Q_{a e}}{Q_{a g}},
$$

where $Q_{a e}$ - cooling capacity of the absorption chiller and according to the suggested design, Fig. 1, it will be equal to the heat of condensation of the vapor compression set.

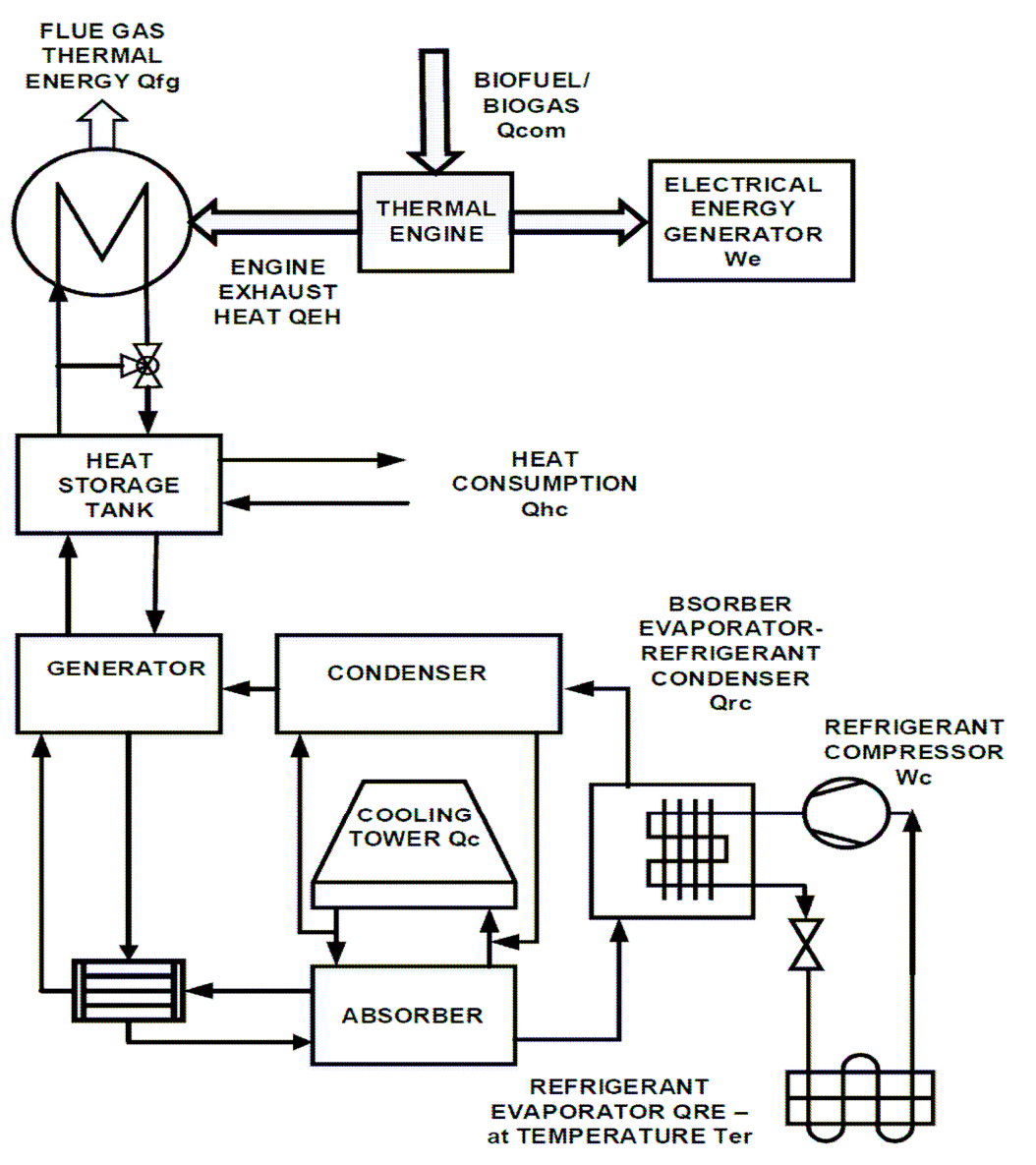

Fig. 1. Trigeneration schematic diagram with hybrid refrigeration system 


$$
\begin{gathered}
C O P_{r}=\frac{Q_{r e}}{W_{c}}, \\
Q_{a e}=Q_{r e}+W_{c}=Q_{r e}\left(1+\frac{1}{C O P_{r}}\right),
\end{gathered}
$$

where $Q_{r e}$ - evaporation heat in the vapor compression set or refrigeration power of the system.

Ratio of refrigeration capacity to heat power of combusted biomass is possible to calculate as

$$
\frac{Q_{r e}}{Q_{\text {com }}}=\frac{0.9 C O P_{a c}}{\left(1+\frac{1}{C O P_{r}}\right)}\left(1-\eta_{e}\right),
$$

Ratio of the vapor compressorelectrical power in vapor compression $W_{r}^{\text {trr }}$ to electrical energy generation $\mathrm{W}_{\mathrm{e}}$ by the thermal engine can be represented as

$$
\frac{W_{r}^{t r}}{W_{e}}=0.9\left(\frac{1}{\eta_{e}}-1\right) \frac{C O P_{a c}}{C O P_{r}+1} .
$$

With the aim to evaluate gain of trigeneration calculations were done based on the above equations(1-10), available technical data for Yazaki absorption chiller using a solution of lithium bromide and water [8] and simulation of the vapor compression cycle for BitzerOpen Screw Compressors OS KA5361-K by [9]. Ammonia $\mathrm{NH}_{3}$ was selected as agent for the compression cycle. The results of calculations are represented in Fig. 2 and Fig.3.

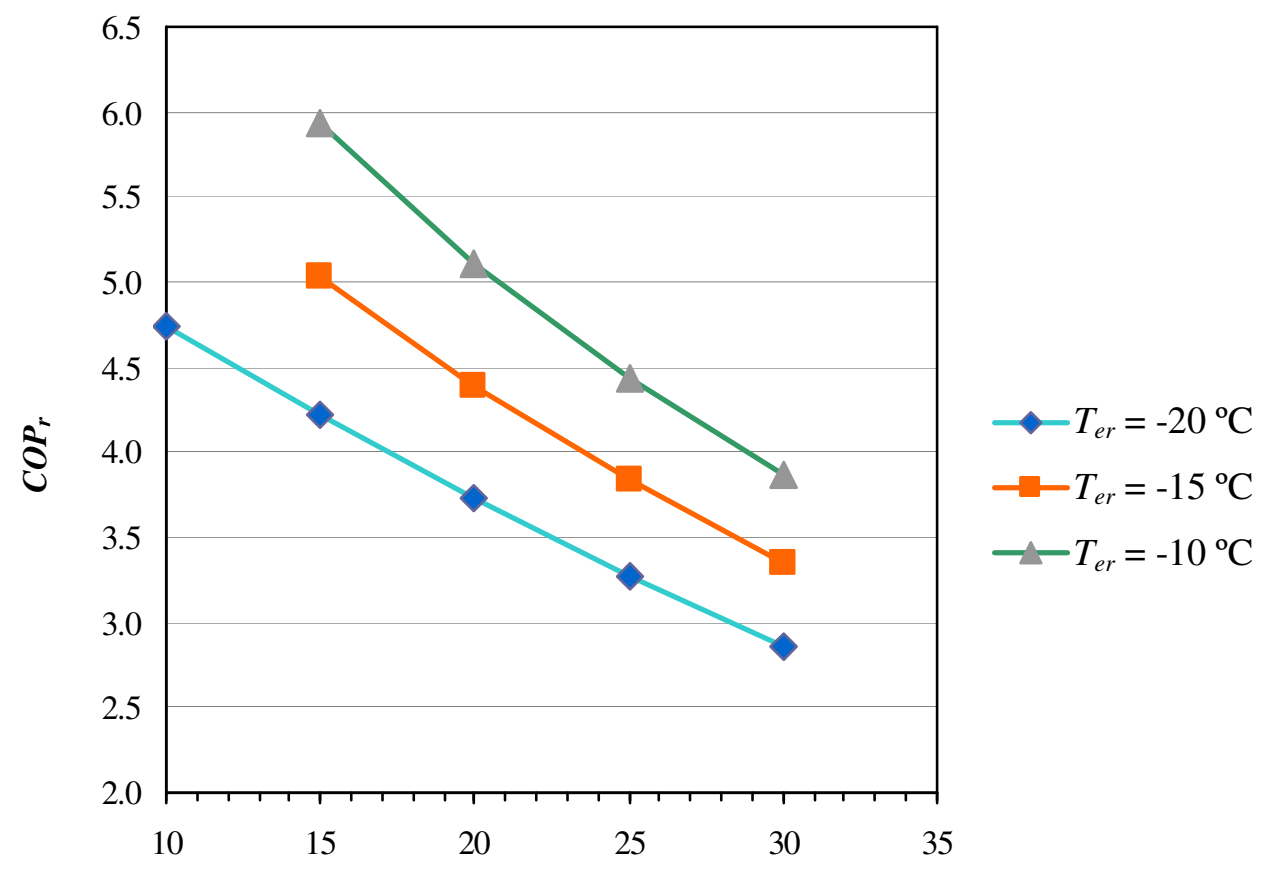

Vapor copression cycle condenser temperature $T_{r c},{ }^{\circ} \mathrm{C}$

Fig. 2. Ratio of refrigerant vapor compressor power to thermal engine electrical energy output for different efficiency of generation and various values of $C O P_{r}$ according to equation (10)

Assessment of hybrid trigeneration efficiency becomes possible by comparison of two diagrams, Fig. 2 and Fig. 3. When temperature of condensation for ammonium drops by operation of the absorption system, $C O P_{r}$ will increase. For ammonium evaporator temperature (refrigeration capacity) $T_{e r}=-10{ }^{\circ} \mathrm{C}$, for condensing temperature $T_{r c}=+30^{\circ} \mathrm{C}$ (when absorption cooling is at low level) $C O P_{r}=2.7$; but for intensive operation of the absorber unit, if $T_{r c}=+10^{\circ} \mathrm{C}$, then $C O P_{r}$ reaches 4.7. All 
these data are available from consideration of Fig.3. Therefore, absorption cooling will enhance the performance of vapor compression refrigeration by increase of $C O P_{r}$. For the purpose of quantity evaluation, it is important to select the appropriate system performance index.

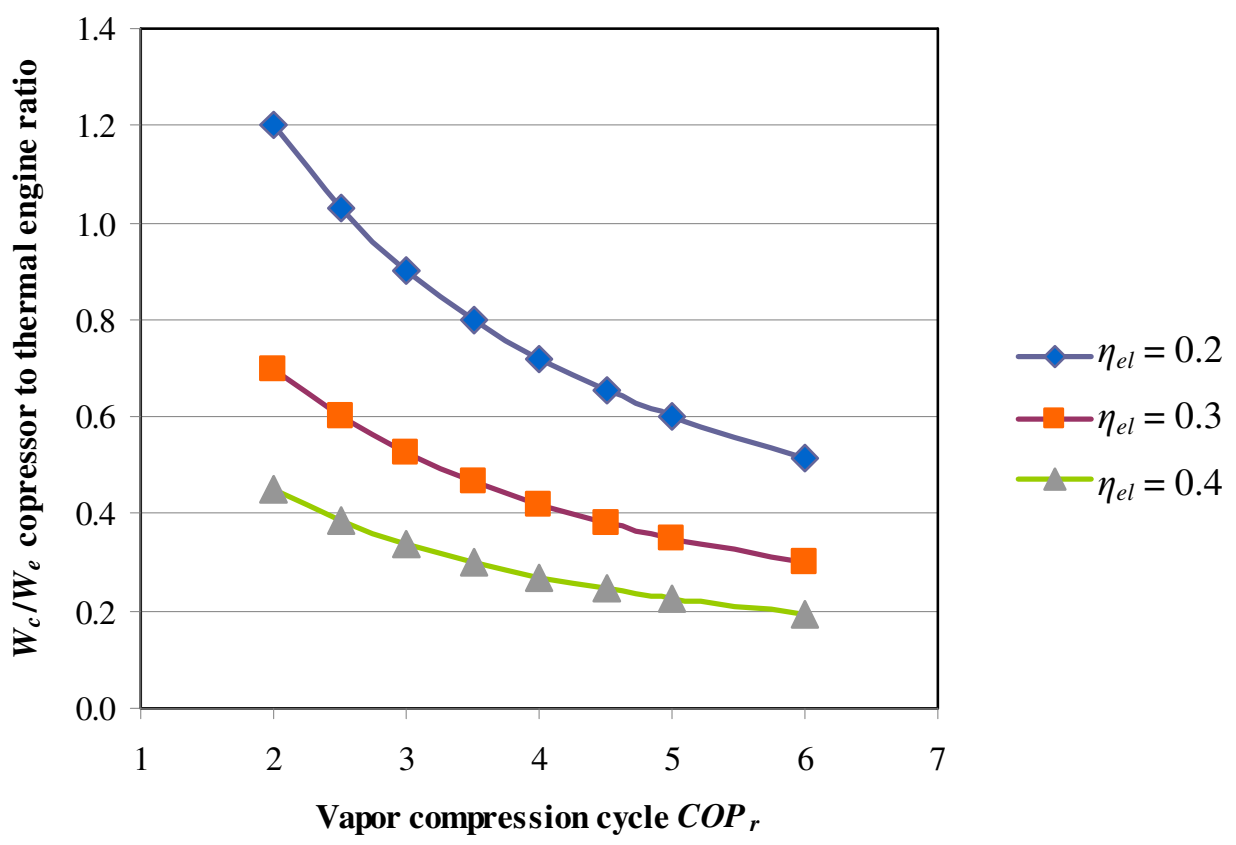

Fig. 3. Efficiency of ammonium refrigeration vapor compressor cycle for differentrefrigeration temperature in evaporator Tre and in condenser Tc. Represented data obtained from Bitzer software simulation

Well known PES or Primary energy saving [2] or primary energy consumption index requests a reference value like the grid efficiency, which is not well developed for the case of trigeneration, due to that we suggest to use PER (Primary energy rate) or energetic efficiency defined as ratio of the useful energy output to the energy by biomass combustion $Q_{\text {com }}$.

$$
P E R=\frac{W_{e}+Q_{r e}+Q_{h c}}{Q_{\text {com }}} .
$$

\section{Results and discussion}

In case of the considered trigeneration with hybrid refrigeration PER equation (11) can be rewritten taken in account that thermal power will be represented only by energy for the absorption cycle driving, so $Q_{h c}=0$, but ratio $Q_{r e} / Q_{c o m}$ will be represented by equation (9). Then calculation of PER will be represented as

$$
P E R=\frac{W_{e}-W_{c}^{t r}+Q_{r e}}{Q_{\text {com }}} .
$$

If substitute in (12) ratio expressions (9) and (10), the following equation will be created for the considered trigeneration assessment

$$
P E R=\eta_{e}+0.9 Q_{a c}\left(1-\eta_{e}\right) \frac{C O P_{r}-1}{C O P_{r}+1} .
$$

If ammonia condensation is going at $T_{r c}=+30^{\circ} \mathrm{C}$ (when absorption cooling is at low level) and $C O P_{r}=2.7$ from Fig.3, then the value of $P E R=0.53$. When absorption cooling will decrease the refrigeration condensation temperature to $T_{r c}=+10{ }^{\circ} \mathrm{C}$ and becomes $C O P_{r}=4.7$, then $P E R$ will grow up to 0.66 . This consideration shows that hybrid cooling will enhance the performance of the system for more than $10 \%$ even without heat duty. Such increase is possible for relatively low electrical 
energy generation efficiency $\eta_{e}=0.2$ (steam turbine or organic Rankine cycle). For generation with higher efficiency performance of hybrid cooling will be at lower efficiency.

\section{Conclusions}

1. The considered hybrid trigeneration system will provide refrigeration at temperatures in the range from $-10{ }^{\circ} \mathrm{C}$ to $-20^{\circ} \mathrm{C}$. Suggested refrigeration temperature will attract wide range of customers, like food industry and supermarkets.

2. Hybrid trigeneration can be an efficient solution for generation from solid biomass by water or organic Rankine cycle with Primary Energy Ratio equal to 0.66. Similar efficiency is possible to expect for the wood generator unit and internal combustion engine. For a biogas plant with the internal combustion engine PER increase will be lower due to better generation efficiency.

3. For sustainable transition from cogeneration to trigeneration it is important to implement it in the framework of the mandatory procurement. The consumption indexes for combined electrical, heat and cooling energy generation should be developed and approved.

\section{References}

[1] Renewable power generation costs in 2017.International Energy Agency. Statistics Report. [online][19.03.2018] Available at: http://www.irena.org/publications/2018/Jan/Renewable-powergeneration-costs-in-2017

[2] Regulations Regarding Electricity Production and Price Determination upon Production of Electricity in Cogeneration. Republic of Latvia Cabinet Regulation No. 221 Adopted 10 March 2009 [online][19.03.2018] Available at: https://likumi.lv/ta/en/id/189260-regulations-regardingelectricity-production-and-price-determination-upon-production-of-electricity-in-cogeneration

[3] Moussawi H.A., Fardoun F., Louahlia-Gualous H. Review of trigeneration technologies: Design evaluation, optimization, decision-making, and selection approach.Energy Conversion and Management, vol. 120, 2016, pp. 157-196.

[4] Quoilin S.,Van Den Broek M., Declaye S., Dewallef P., Lemort V.Techno-economic survey of Organic Rankine Cycle (ORC) systems. Renewable andSustainableEnergyReviews, vol.22, 2013, pp. 168-186.

[5] Ketfi O., Merzouk M., Merzouk N.K., Bourouis M. Feasibility study and performance evaluation of low capacity water- $\mathrm{LiBr}$ absorption cooling systems functioning in different Algerian climate zones. International journal of refrigeration, vol.82, 2017, pp. 36-50.

[6] Lychnos G., Tamainot-Telto Z. Performance of hybrid refrigeration system using ammonia. Applied Thermal Engineering, vol.62, 2014, pp. 560-565.

[7] Wang J., Li X., Wang B., Wu W., Song P., Shi W. Performance Comparison between an Absorption-compression Hybrid Refrigeration System and a Double-effect Absorption. Refrigeration System. Procedia Engineering, vol.205, 2017, pp. 241-247.

[8] Yazaki WFC-S Series Water - Fired Chiller/Chiller-Heater [online][19.03.2018] Available at: http:// www.yazakienergy.com/docs/WFCSUL-SBDG1-2A-0313.pdf

[9] BITZER Software v6.7.0 rev1849 [online][19.03.2018]

Available at: https://www.bitzer.de/websoftware 